\title{
Desiccation intolerance of the red palm weevil, Rhynchophorus ferrugineus (oliv) adults in relation to their cuticular hydrocarbons
}

\author{
Monzer, M.A. and Hesham A. Srour \\ Plant Protection Research Institute, Agricultural Research Center, Dokki, Giza, Egypt. \\ Corresponding author e-mail: monsangk@ hotmail.com
}

\begin{abstract}
The desiccation tolerance of red palm weevil (RPW), Rhynchophorus ferrugineus was investigated in the laboratory. Adults exposed to 35 or $75 \%$ relative humidity showed high rate of water loss. Water loss rate averaged $2.32 \pm 0.35$ and $6.71 \pm 0.73$ $\mathrm{mg} / \mathrm{g}$ fresh body weight/hr at 35 or $75 \% \mathrm{RH}$, respectively, and cumulative loss increased with time. Adults exposed to $35 \% \mathrm{RH}$ died within a maximum of 4 days. Cuticular hydrocarbons (CHCs) were isolated and identified from adults to elucidate the physiological basis of their intolerance to desiccation. They were dominated by saturated n-alkanes $(75 \%)$, while the ester compound 1-henicosyl formate, the fatty alcohol 3-(E) eicosanol and the alkene tricosene represented $25 \%$ of total surface CHCs. The desecration intolerance of weevils was attributed to the presence of relatively high proportion of 1-henicosyl formate $(17.5 \%)$ which could form large pores within the waxy waterproofed CHCs layer of weevils.
\end{abstract}

Key words: Desiccation, red palm weevil, cuticular hydrocarbons

\section{INTRODUCTION}

Red palm weevil, Rhynchophorus ferrugineus Oliv (Coleoptera: Curculionidae) is the most dangerous and destructive pest of date palm in the Middle-East (Abraham et al., 1998). Since it had been introduced to Egypt at1992 (Cox, 1993) thousands of healthy trees were damaged or lost (El-Sebaey, 2004). In infested plantations, yields have been estimated to drop from 10 tonnes to 0.7 tonnes per hectare (Singh and Rethinam, 2005). Furthermore, $R$. ferrugineus is a strong flyer. This increase the weevil's ability to disperse, colonize and breed at new sites (Murphy and Briscoe, 1999). However, longevity, activity and behavior of adult weevils are greatly affected by humidity. Leefmans (1920) mentioned that adult weevils were negatively affected by a dry environment. Nirula (1956) found that RPW adults survived less than six days when kept in a dry environment. Aldryhim and Kalial (2003) found that both sexes were survived up to 3 and 39 days in dry and moist peat moss, respectively. Giblin-Davis and Howard (1989) and Weissling and Giblin-Davis (1993) mentioned that adults of the closely related species, Rhynchophorus cruentatus is susceptible to significant water loss in dry environments and suffered from high mortality when placed in Petri-dishes that lacked moisture. They suggested that the desiccation intolerance $R$. cruentatus could be attributed to the high cuticular permeability of this weevil.

Adult desiccation intolerance is of particular interest in RPW because: (1) it may therefore serve as a physiological biomarker, (2) it is a functional character which is likely to be of significance for decision making for prediction the dispersal ability of RPW in new area. Thus, in the present study, the effect of the humidity on the rate of water loss and survival of RPW adults was investigated. Also, because water loss 
through the cuticle of most insects is regulated by the outermost cuticular hydrocarbons layer, the composition of CHC of the adult RPW was investigated in this study to elucidate the physiological basis of the desiccation intolerance in RPW adults.

\section{MATERIAL AND METHODS}

RPW collection: Random samples of RPW adults were collected from infested palm trees located at El-kasassen, Ismailia Governorate, Egypt.

Water loss experiments: RPW Adults were weight and placed individually into each of 24 glass Petri plates (15 cm-diameter), each containing a 7.5 -cm-diameter Whatman No.1 filter paper disk. The Petri plates were kept inside two desiccators, one of which contained $100 \mathrm{ml}$ of saturated $\mathrm{NaCl}$ solution, and the other contained saturated $\mathrm{MgCl}_{2}$ to maintain $75 \%$ and $33 \% \mathrm{RH}$, respectively (Woodrow et al., 2000). After tightly covering with their lids, desiccators were maintained inside incubator at $25^{\circ} \mathrm{C}$. After $24,48,72$ and $96 \mathrm{hrs}$, the weevils were weight and were returned quickly to the desiccators. When a weevil was deemed dead, as indicated by the inability to right itself or move its limbs when agitated, it was immediately removed and weight for determination of the critical water loss. Relative humidity during each exposure was monitored by an electronic laboratory hygrometers located inside the desiccators.

CHC Extraction: CHC were extracted according to the method described by Woodrow et al. (2000). Nine adults were first killed by freezing. CHCs were extracted from the surface of specimens by placing each adult in $10 \mathrm{ml} n$-hexane for 5 min with agitation. The extracts were pipetted through $4 \mathrm{~cm}$ of activated silica gel (100-200 mesh); in 5-mm (i.d.) Pasteur pipette minicolumns to isolate CHC components. The extracts were then evaporated to dryness under nitrogen and dissolved in $120 \mu \mathrm{l} n$-hexane for GC-MS analysis.

GC-MS Analysis: Identification of compounds in CHCs extracted from RPW adults was carried out with a HP 5972A mass spectrometer (MS) coupled to HP-6890 gas-chromatography (GC) equipped with a HP-5MS capillary column (30 m x 0.32 ID, $0.25 \mu \mathrm{m}$ film thickness). Electron impact (EI) mass spectra were obtained at 70 $\mathrm{eV}$ and the instrument scanning from 35 to $700 \mathrm{amu}$. Helium was used as the carrier gas at a flow rate of $1 \mathrm{ml} / \mathrm{min}$. Injector temperature was $250^{\circ} \mathrm{C}$; detector temperature was $280^{\circ} \mathrm{C}$, and split was $10: 1$. Oven temperature was programmed from $35^{\circ} \mathrm{C}(5$ min) to $80^{\circ} \mathrm{C}$ at $10^{\circ} \mathrm{C} / \mathrm{min}$ and to $250^{\circ} \mathrm{C}$ at $4^{\circ} \mathrm{C} / \mathrm{min}$. Integration of peaks, drawing calibration table, and standard curve were performed using HP-Chemstation software. Identification of constituents present was based on computer matching against the library spectra (Wiley275L), built up using pure substances and components of known constituents. GC-MS peak areas were converted to percentages of the total hydrocarbon fraction. Compounds representing $<1 \%$ of the total were not considered in the data.

\section{Statistical analysis:}

Data were subjected to analysis of variance (Student t-test) at $\mathrm{P}<0.05$ using the software package Costat (Cohort Inc, Berkeley, USA) Results are recoded as mean \pm standard deviation (SD).

\section{RESULTS AND DISCUSSION}

Results in Table 1 and Fig. 1 show that water loss in RPW adults maintained at $35 \% \mathrm{RH}$ was much higher than those maintained at $75 \% \mathrm{RH}$, with average rate of $2.32 \pm 0.35$ and $6.71 \pm 0.73 \mathrm{mg}$ water released/g fresh body weight $/ \mathrm{hr}$, respectively. 
The differences in water loss between RPW maintained at $75 \% \mathrm{RH}$ and $35 \% \mathrm{RH}$ were significant at all time intervals $(\mathrm{P}<0.05$, T-test $)$. RPW maintained at $35 \% \mathrm{RH}$ for more than $72 \mathrm{hrs}$ died essentially within the followed $24 \mathrm{hrs}$ when their water loss reached critical level of $520 \pm 27 \mathrm{mg}$ water/g fresh body weight. Mean longevity of RPWs maintained $35 \% \mathrm{RH}$ was significantly lower $(\mathrm{P}<0.05$, T-test $)$ than those maintained at $75 \% \mathrm{RH} \quad(3.3 \pm 0.25$ vs. $15 \pm 3$ days, respectively). These results are in agreement with that of Aldryhim and Kalial (2003) who mentioned that RPW adults were survived up to three days in dry peat moss. Results also indicate that even at relative humidity as high as $75 \% \mathrm{RH}$ the rate of water loss of RPW was still high compared with many other beetles. For example, water loss of adult of tenebrionid beetles, Stenocara gracilipes (Solier) was only $1.8 \square 0.5 \mathrm{mg} / \mathrm{g}$ body weight/hr at $15 \% \mathrm{RH}$ (Naidu 2001), which 2 fold less than that of RPW at 75\% RH. High transpiration rates under different $\mathrm{RH}$ were also recorded in $R$. cruentatus (Weissling and Giblin-Davis, 1993).

RPW develop surrounded by moist fermenting tissues inside palm trunks in a relatively stable climate where temperatures are moderate $\left(19 \pm 1^{\circ} \mathrm{C}\right)$, relative humidity are high and evaporation of water was absent or negligible. When RPWs leave palm trunks after maturation for oviposition, they exposed to daily higher temperature and low relative humidity compared with the internal palm trunk environment. This new situation represents high environmental stresses on them. It is not surprising then that RPW individuals hide their bodies inside moist soil that acts as a temporary harborage for moisture, shade and shelter during the day (Abbas $\boldsymbol{e t}$ al., 2001 and Aldryhim and Khalia, 2003) to regulate water loss.

Table.1. Effect of relative humidity on $R$. ferrugineus adults

\begin{tabular}{|l|c|c|}
\hline Parameter & $75 \% \mathrm{RH}$ & $35 \% \mathrm{RH}$ \\
\hline $\begin{array}{l}\text { Average hourly water loss (mg } \\
\text { water/g fresh body weight/hr) }\end{array}$ & $2.32 \pm 0.35 \mathrm{a}$ & $6.71 \pm 0.73 \mathrm{~b}$ \\
\hline Mean longevity (days) & $15 \pm 3$ days b & $3.3 \pm 0.25 \mathrm{a}$ \\
\hline $\begin{array}{l}\text { Critical water loss (mg water/g } \\
\text { fresh body weight) }\end{array}$ & \multicolumn{2}{|c|}{$520 \pm 27$} \\
\hline
\end{tabular}

Values in the same raw followed by different letters are significantly differ $(\mathrm{P}<0.05, \mathrm{~T}$-test $)$

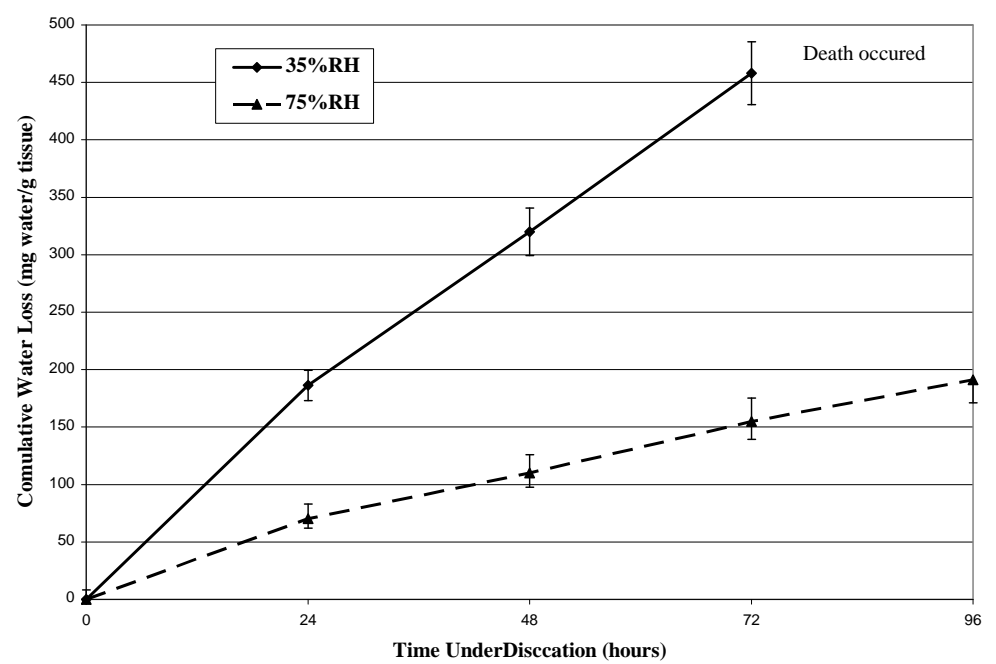

Fig (1): Mean cumulative water loss by adults of $R$. ferrugineus at 35 and $75 \% \mathrm{RH}\left(25^{\circ} \mathrm{C}\right)$. 
The rate of water loss and tolerance as a physiological basis explain RPW behavior under field conditions were determined. Clearly, it would be interesting to gain a more detailed understanding of the specific physiological mechanisms responsible for RPW desiccation intolerance. Insects lose water through three distinct routes: cuticular, respiratory and excretory (Chapman, 1969). However, in most insect species studied, cuticular transpiration accounts for more than $90 \%$ of total water loss under desiccation (Gibbs, 2002). Of the cuticular layers, the outermost epicuticular lipid layer provides the primary barrier to transpiration and evaporation through the cuticle (Gibbs, 1998). Weissling and Giblin-Davis (1993) mentioned that preliminary GC analysis of hexane washes of $R$. cruentatus adults, a species closely related to RPW, showed no detectable hydrocarbons. In contrary, our analyses of surface hydrocarbons extracted from RPW adults (Table 2 and Fig. 2) revealed the presence of 10 compounds, 7 of them were unbranched saturated n-alkanes, one unsaturated alkene compound (Tricosene), one ester compound (1-henicosyl formate) and one fatty alcohol compound (3- eicosanol). The percentage of saturated unbranched hydrocarbons was $75 \%$, while the remaining three compounds represented $25.17 \%$ of the total CHCs.. The carbon number of the identified compounds ranged from $\mathrm{C} 17$ to $\mathrm{C} 35$. $n$-tricosane was the major compound, represented $30 \%$ of cuticular hydrocarbons followed by $n$-nonacosane and 1-henicosyl formate.

Table 2. Cuticular hydrocarbons of adults of R. ferrugineus adults.

\begin{tabular}{|c|c|c|c|c|}
\hline $\begin{array}{c}\text { Retention } \\
\text { Time (RT) }\end{array}$ & Hydrocarbons & $\%$ CHC & $\begin{array}{c}\text { Molecular } \\
\text { formula }\end{array}$ & $\mathrm{T}_{\mathrm{m}}\left({ }^{\circ} \mathrm{C}\right) *$ \\
\hline 10.89 & n-Heptadecane & 2.3 & $\mathrm{n} \mathrm{C}_{17} \mathrm{H}_{36}$ & 22 \\
\hline 12 & n-Nonadecane & 2.5 & $\mathrm{n} \mathrm{C}_{19} \mathrm{H}_{40}$ & 35 \\
\hline 18.6 & Tricosene & 2.2 & $9 \mathrm{C}_{23} \mathrm{H}_{46}$ & $<20$ \\
\hline 21.04 & n-Heneicosane & 6 & $\mathrm{C}_{21} \mathrm{H}_{44}$ & 40 \\
\hline 22.84 & n-Tricosane & 30 & $\mathrm{n} \mathrm{C}_{23} \mathrm{H}_{48}$ & 47 \\
\hline 23.91 & n-Pentacosane & 6.2 & $\mathrm{n} \mathrm{C}_{25} \mathrm{H}_{52}$ & 54 \\
\hline 24.85 & 1-Henicosyl formate & 17.54 & $\mathrm{C}_{18} \mathrm{H}_{38} \mathrm{O}$ & $<21$ \\
\hline 25.17 & n-Nonacosane & 20.16 & $\mathrm{C}_{29} \mathrm{H}_{60}$ & 64 \\
\hline 26.05 & 3- (E)Eicosanol & 5.43 & $\mathrm{C}_{20} \mathrm{H}_{42} \mathrm{O}$ & $<20$ \\
\hline 28.73 & n-hexatriacontane & 7.67 & $\mathrm{C}_{36} \mathrm{H}_{74}$ & 76 \\
\hline & Saturated compounds & 74.83 & & \\
\hline & Unsaturated compounds & 25.17 & & \\
\hline
\end{tabular}

*Melting temperature values (according to Gibbs, 2002)

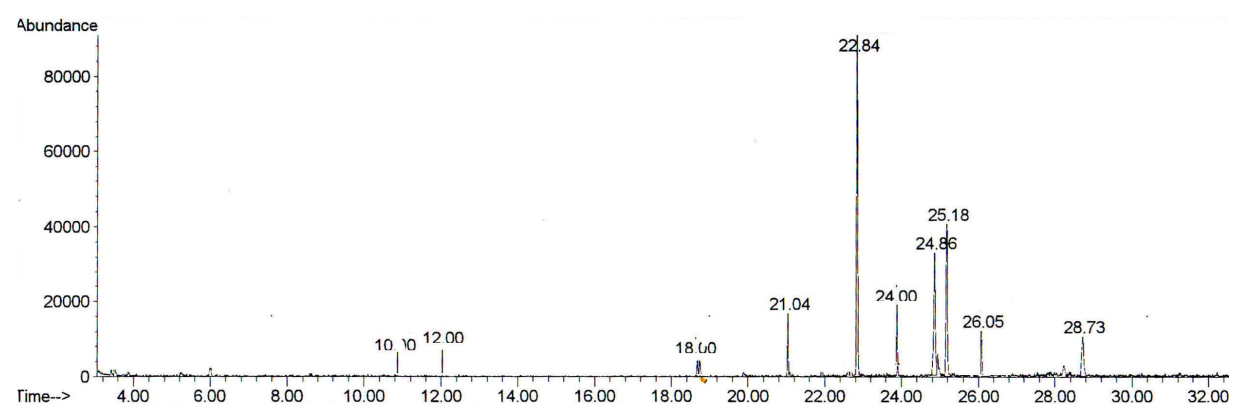

Fig (2): Gas chromatogram of the hydrocarbons obtained from the cuticle surface of $R$. ferrugineus adults 
Most saturated unbranched hydrocarbons are crystalline and solid under environmental temperature and are effective in waterproofing the surface of insects and then reduce water loss rate (Woodrow et al., 2000). Surface lipid hydrocarbon need to be melted or partially melted for cuticular permeability to increase (Gibbs, 2002). The melting temperature $\left(T_{m}\right)$ of the identified major saturated hydrocarbons compounds in this study ranged from $41^{\circ} \mathrm{C}$ for $n$-heneicosane to $76^{\circ} \mathrm{C}$ for $n$ hexatriacontane, indicating good waterproofing properties under high temperature and desiccation stress. However, $25 \%$ of the identified RPW surface hydrocarbons were unsaturated and ester compounds with low melting temperature $\left(<20^{\circ} \mathrm{C}\right)$. The predominant compound of them; 1-henicosyl formate is derivative of $n$-heneicosane contains one ester bond and one duple bond. The presence of an ester linkage and duple bond decreases $T_{m}$ of 1-henicosyl formate by about $21^{\circ} \mathrm{C}$ or more than the parent compound $n$-heneicosane (Patel et al., 2001), thus, $\mathrm{T}_{\mathrm{m}}$ of 1-henicosyl formate is expected to be lower than $20^{\circ} \mathrm{C}$. This indicating that about 25 of the hydrocarbons in RPW cuticle are present in liquid state at temperature $>20^{\circ} \mathrm{C}$. Furthermore, Gibbs (2002) suggests that solid and liquid cuticular hydrocarbons do not mixed together but phase separation occurs at ecologically relevant temperatures. At temperature $>20 \mathrm{C}$, the melted compounds, especially 1-henicosyl formate act as a large pores deposited through the waxy $n$-alkane waterproof cover of RPW epicuticle. Thus, deposition of large proportion of 1-henicosyl formate in RPW cuticle may be responsible for the higher transpiration rate. It should be mentioned that 1-henicosyl formate is not previously reported from other insects, thus we feel that it could be used for species discrimination in palm weevils.

The studies showed that activity of RPW adults is high in October - November, and March -April and prefer to fly between twelve at mid night and six in the morning (El-Garhy, 1996, El-Ezaby et al., 1998 and Faleiro, 2006), could confirm our conclusion. At such months and daily period, temperature is generally below the melting temperature of 1-henicosyl formate $\left(21^{\circ} \mathrm{C}\right)$.

Most insects synthesize a small quantities of compounds with low melting temperature in their cuticular lipids for several potential beneficial such as: evaporative during flight, improved dispersal of anti-predator anti-microbial compounds and, most important, improved dispersal of pheromones across the cuticle with the melted lipids (Gibbs, 2002). Males and females of the palm weevils produce relatively large quantity of several volatile pheromone related compounds for ìntraspecific chemical communication. Males produce aggregation pheromone. Also, studies showed that females of the palm weevil $R$. palmarum produce cuticle-bound courtship pheromones (Giblin-Davis et al., 1996). The morphological examination of pheromone glands of $R$. palmarum, suggesting that the insect does not possess a reservoir to store the pheromone. The secreted pheromone could be impeded in and dispersed through the melted hydrocarbon for slow release (Sanchez et al., 1996). It is probable that it is also true for RPW, given the close phylogenetic relationship and similarity of behavior between $R$. palmarum and RPW. Thus, the presence of high proportion of liquid lipids in epicuticle is of grate importance for RPW communication, although they decrease its desiccation tolerance.

\section{REFERENCES}


Abbas, M. S., Hanounik S. B., Mousa S. A. and Mansour M. I. (2001). On the pathogenicity of Steinernema abbasi and Heterorhabditis indicus isolated from adults Rhynchophorus ferrugineus (Coleoptera). Intern. J. Nematol. 11(1): 69-72.

Abraham, V.A., Al-Shuaibi M.A, Faleiro J.R, Abuzuhairah R.A., and Vidyasagar P.S. (1998). An integrated management approach for red palm weevil, Rhynchophorus ferrugineus Oliv., a key pest of date palm in the Middle East. Sultan Qubus Univ. J. Sci. Res., Agrie. Sci. 3:77-83

Aldryhim Y. and Khalil A. (2003). Effect of Humidity and Soil Type on Survival and Behavior of Red Palm weevil, Rhynchophorus ferrugineus (Oliv.) Adults. Agricultural and Marine Sciences, 8(2):87-90

Chapman, R.F. (1969). The insect's structure and function. American Elsevier. New York.

Cox, M. L. (1993). Red palm weevil Rhynchophorus ferrugineus in Egypt. FAO Plant Prot. Bull. 41(1): 30-31.

El-Ezaby, F, Khalifa O., and El-Assal A. (1998). Integrated pest management for the control of red palm weevil, Rhynchophorus ferrugineus Oliv., in the United Arab Emirates, Eastern region, Al-Ain. Proceedings of the First Internat. Conference on Date Palm pp. 269-281, March 1998, Al-Ain, UAE.

El-Garhy, M. E. (1996). Field evaluation of the aggreagation pheromone of the red palm weevil, Rhynchophorus ferrugineus in Egypt. Brighton crop protection conference: Pest and diseases. 3: 1059-1064.

EL-Sebaey Y. (2004). Field evaluation of certain insecticides against red palm weevil Rhynchophorus ferrugineus Oliv. (Coleoptera, Curculionidae) in Egypt. Egypt. J. Agric. Res. 82(4): 1591-1599

Faleiro, J.R. (2006). Insight into the management of red palm weevil Rhynchophorus ferrugineus Olivier: Based on experiences on coconut in India and date palm in Saudi Arabia. In: Fundación Agroalimed (Ed.). I Jornada Internacional sobre el Picudo Rojo de las Palmeras (November,2005). Fundación Agroalimed. Valencia. Spain, pp. 35-57.

Gibbs A.G. (2002). Lipid melting and cuticular permeability: new insights into an old problem. J. Insect Physiol. 48: 391- 400

Gibbs A, P. (1995). Physical properties of insect cuticular hydrocarbons: the effects of chain length, methyl-branching and unsaturation. Comp Biochem Physiol B 112:243-249.

Giblin-Davis, R. M. and Howard E. W. (1989). Vulnerability of stressed plants to attack by Rhynchophorus cruentatus (Coleoptera: Curculiondae) and insecticides control of the pest. J Econ Entomol, 82:1185-1190.

Giblin-Davis, R. M.; Oehlschlager, A. C.; Perez, A.; Gries, G.; Gries, R.; Weissling, T.J.; Chinchilla, C.M.; Peña, J.E.; Hallett, R.H.; Pierce, H.D. and Gonzalez L.M. (1996). Chemical and Behavioral Ecology of Palm Weevils (Curculionidae: Rhynchophorinae). Florida Entomol. 79(2): 153 -158.

Leefmans, S. 1920. De Palmsnuitkever (Rhynchophorus ferrugineus Oliv.). Meded. Inst. Plziekr. 43:1-90

Murphy, S. T. and Briscoe B. R. (1999). The red palm weevil as an alien invasive: biology and the prospects for biological control as a component of IPM. Biocontrol News and Information 20(1):35-46.

Naidu S.G. (2001). Water balance and osmoregulation in Stenocara gracilipes, a waxblooming tenebrionid beetle from the Namib Desert. J. of Insect Physiol. 47: $1429-1440$ 
Nirula, K.K. (1956). Investigation on the pests of coconut palm, Rhynchophorus ferrugineus. Indian Coconut J. 9:229-247.

Patel S., Nelson D.R. and Gibbs A.G. (2001). Chemical and Physical Analyses of Wax Ester Properties. J. Insect Sci., 1(4): 1-5

Sanchez P., Cerda H., Cabrera A., Caetano F.H., Materan M., Sanchez F. and Jaff K. (1996). Secretory mechanisms for male produced aggregation pheromone of the red palm weevil, Rhynchophorus palmarum L. (Coleoptera: Curculionidae). J. Insect Physiol. 42:1113-119.

Singh S. P. and Rethinam P. (2005). Trapping-a major tactic of BEPM strategy of palm weevils. Cord, 21(1): 57-79

Weissling, T. J. and Giblin-Davis, M. (1993). Water loss dynamics and humidity preference of Rhynchophorus cruentatus (Coleoptera: Curculionidae) adults. Environ. Entomol. 22(1): 93-98

Woodrow, R. J.; Grace, J. K.; Nelson, L. J. and Haverty, M. I. (2000). Modification of cuticular hydrocarbons of cryptotermes brevis (isopteran: Kalotermitidae) in response to temperature and relative humidity. Environ. Entomol. 29(6):11001107.

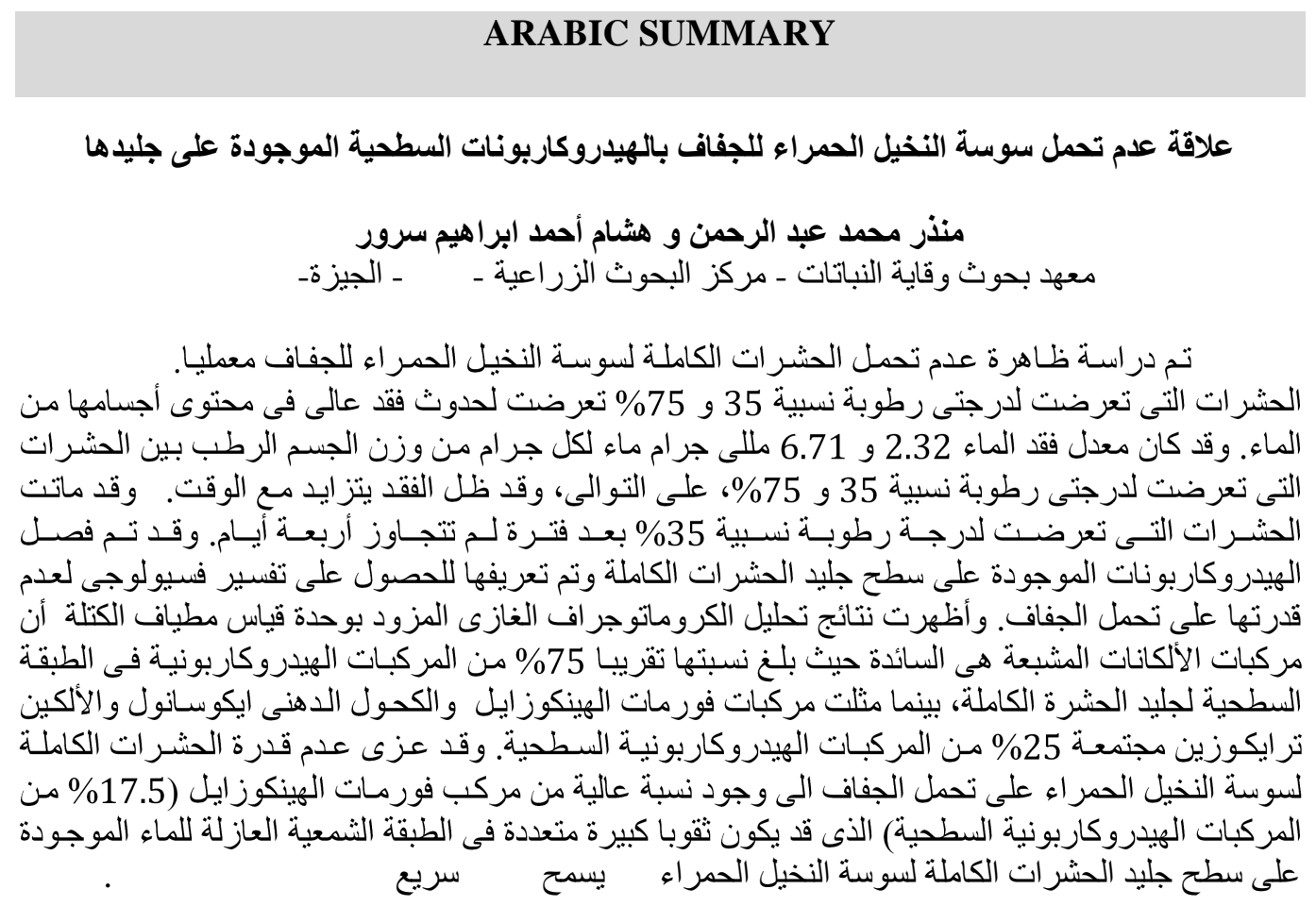

